\title{
Derechos humanos y actual racismo en las migraciones de la africanidad
}

\author{
Human rights and current racism in the migrations of Africanity
}

\section{Cyril Omeir $^{1}$}

\author{
Nadie nace odiando a otra persona por el color de su piel o su origen o su religión. \\ La gente aprende a odiar, y si ellos pueden aprender a odiar, también se les puede enseñar a amar. \\ El amor llega más naturalmente al corazón humano que su contrario.
}

Nelson Mandela ${ }^{2}$

\section{Resumen}

Esta conferencia magistral ha abordado el tráfico de esclavos desde los siglos XV y XVI, la migración actual de los africanos hacia los Estados Unidos hecho que se criminaliza y se mediatiza por la manipulación de los medios periodísticos y las instituciones del Estado de Panamá, Costa Rica y Nicaragua; el objeto es hacer un recorrido de las páginas de la historia a través de una hermenéutica que devela andamiajes de corrupción y destrucción por monopolios y políticos corruptos de las localidades desde el África y el origen mismo del capitalismo en la imposición de la esclavitud. Se plantean retos como la transformación de las universidades y la fundación de Universidades Interculturales Indígenas que, en acompañamiento a las comunidades afrodescendientes, indígenas y mestizos en la construcción de las bases del pensamiento descolonizador y se trazan las perspectivas del desarrollo auto sostenible e integral.

Palabras clave: esclavitud; africanidad; racismo; migración y sistema educativo; educación intercultural.

\section{Abstract}

This keynote speech has addressed the slavery trade since the 15th and 16th centuries; the current migration of Africans to the United States is a fact, which it is criminalized and mediated by the journalistic media manipulation and the institutions of Panama, Costa Rica and Nicaragua States. The objective is to make a tour of the pages of history through a hermeneutics that reveals the scaffolding of corruption and destruction by monopolies and corrupt politicians of the localities from Africa and the very origin of capitalism in the imposition of slavery. Challenges are posed, such as the transformation of universities and the founding of Indigenous Intercultural Universities that, in support of Afro-descendant, indigenous and mestizo communities, in the construction of the foundations of decolonizing thought and the perspectives of self-sustainable and integral development.

Key words: slavery; africanity; racism; migration and education system; intercultural education.

\footnotetext{
1 Doctor en Odontología. Secretario General de la Universidad de las Regiones Autónomas de la Costa Caribe Nicaragüense. Correo: secretario.general@uraccan. edu.ni ORCID es: https://orcid.org/0000-0002-2761-7938

2 Nelson Rolihlahla Mandela (Mvezo, Unión Sudafricana; 18 de julio de 1918-Johannesburgo, Gauteng, Sudáfrica; 5 de diciembre de 2013) fue un abogado, activista contra el apartheid, político y filántropo sudafricano que actuó como presidente de su país de 1994 a 1999 . Fue el primer mandatario de raza negra que encabezó el poder ejecutivo, y también el primero en resultar elegido por sufragio universal en su país.
}

Recibido: 17/01/2018 - Aprobado: 05/04/2018 
Género e interculturalidad

\section{Introducción}

La llegada de los afrodescendiente a América se remonta a los siglos XV y XVI cuando fueron traídos contra su voluntad por portugueses, españoles, ingleses, holandeses y franceses para trabajar como esclavos en las grandes plantaciones de café, banano, algodón, tabaco, caña de azúcar, para la minería y trabajos domésticos. Constituye la primera migración transcontinental masiva en la historia del hemisferio y de la humanidad ${ }^{3}$.

El tráfico de esclavos provocó estragos en África, los cuales hoy se hacen sentir. Durante cuatro siglos este continente fue escenario de guerras y razzia por la captura de esclavos. Millones de africanos fueron exportados para tierras lejanas, otros tantos millones murieron en largas marchas hasta la costa y en los senzalas o lugares de reconcentración a la espera de ser embarcados. Este éxodo forzado de millones de personas provocó la disminución demográfica de la población, ya que los hombres y mujeres en edad de procreación eran vendidos.

No existen cifras exactas de la magnitud del comercio esclavista en América, pero desde mediados del siglo XV por lo menos 13 millones de africanos desembarcaron en las costas del Nuevo Mundo, número engañoso si se tiene en cuenta que tres esclavos de cada cuatro morían en el trayecto. Un crimen de lesa humanidad que nunca ha sido reparado y que sin el cual no se habrían levantado los imperios ingleses, franceses, holandeses, españoles y portugueses en el continente.

Algunos investigadores llegan a decir que entre los siglos XV y XIX el continente perdió más de cien millones de hombres y mujeres jóvenes. Varias regiones africanas quedaron casi totalmente despobladas. El investigador André Gunder Frank ${ }^{4}$ en su libro La Acumulación Mundial 1492-1789 señala la cifra de 13,750.00o esclavos traídos contra su voluntad a América entre los siglos XVI y XIX, a lo que el investigador Peregalli ${ }^{5}$ añade un $25 \%$ por muertes en el trayecto y un $25 \%$ por muertes en África por motivo de las guerras de captura, lo que da un total de 20, 625,000 africanos perdidos para el continente en ese período.

Algunos consideran que los afrodescendientes por su origen, traídos como esclavos no tienen derechos; permítanme precisar: Si existen personas que tienen derechos en esta nuestra América Latina y el Caribe son la gente negra, por su gran contribución al desarrollo de las Américas y el alto costo que nuestros ancestros pagaron para que nosotros el día de hoy estemos aquí. Como expresamos anteriormente fueron violentamente expulsados de sus comunidades y obligados a cruzar el Océano, la única razón porque nosotros estamos aquí el día de hoy es por su gran fortaleza física y espiritual, si señores y señoras. Ellos pagaron un muy alto precio para que nosotros podamos estar aquí el día de hoy.

África es un continente no sólo con hambres y sequías. Es también civilización, historia, origen, cultura, música, oro, diamantes, cobalto, coltan y recursos naturales que son parte de nuestra herencia. Esta historia es origen de sangre derramada y dolor, incertidumbre, esclavitud en función del empoderamiento de los países ricos de Europa desde el auge del Renacimiento y la industrialización, como fenómenos del capitalismo, la alienación e inequidades manifiestas en el proceso del desarrollo comercial, el descubrimiento de nuevas rutas de mercadeo, la ciencia al servicio de las clases poderosas que han menospreciado la vida a lo largo de cinco siglos de opresión y explotación, hasta orillarnos en el siglo XXI y el neocolonialismo con nuevas expresiones racistas y nuevas formas de esclavitud, invisibilizados por la muestra de catástrofes, discriminación y la guerra.

\footnotetext{
3 Hugh Thomas. Inició sus estudios en una escuela privada de Doset y en el Queens' de la Universidad de Cambridge, donde obtuvo un título de Bachiller en Artes (1951); luego amplió estudios en La Sorbona (París). Obtuvo un premio Tripos en Historia (1952) y en 1953 presidió la Cambridge Unio Society. De 1954 a 1957 trabajó para el Foreign Office, en parte como secretario de la delegación británica dentro de una subcomisión de la Comisión de Desarme de la ONU y en 1955 hizo su primer viaje a España.

4 André Gunder Frank (Berlín, 24 de febrero de 1929 - Luxemburgo, 23 de abril de 2005) fue un economista y sociólogo alemán y uno de los creadores de la teoría de la dependencia en los 60.

5 Enrique Peregalli. Uruguayo, el autor es formado en Filosofía por el Instituto Filosófico y Teológico de Uruguay y en Historia por la USP.
} 
Karl Marx ${ }^{6}$ en su influyente historia económica del capitalismo, en su obra El Capital afirmó que la conversión de África en una madriguera para la caza comercial de pieles negras (así se refería al comercio de esclavos) fue el halagüeño amanecer de la era de la producción capitalista. Marx opinaba que el comercio de esclavos era parte de lo que denominaba la "acumulación primitiva del capital europeo, la acumulación no capitalista de riqueza que había procedido y creado las condiciones financieras para la industrialización británica."

Eric Eustace Williams ${ }^{7}$ opina que la esclavitud de africanos fue un elemento esencial de la Revolución Industrial, y que la riqueza europea es resultado de la esclavitud. Lo triste de toda esta historia es que la Iglesia Católica que debía en el momento condenar la esclavitud por considerarla ultrajante y contra los principios y enseñanzas de nuestro señor Jesucristo, ya que para la fe en el Cristianismo todos son hijos de Dios, no lo hizo más bien vemos que en El Concilio de Trento decretaba la Bula Papal de 1458 (Decreto) que establecía que "los negros no tenían alma", no eran humanos y por ende, susceptibles de ser sometidos a la esclavitud.

Nada de ello ofendería a Dios. Si bien Juan Pablo II ${ }^{8}$, pidió perdón en África por esa bula, ello no hace olvidar que ochenta millones de africanos fueron sometidos a la esclavitud. En la Bula Papal Sublime, Dios, expresa el Papa Pablo III, Nosotros, pues que aunque indignos, ejercemos en la Tierra el poder de Nuestro Señor, y luchamos por todos los medios para traer el rebaño perdido al redil que se nos ha encomendado, consideramos sin embargo que los indios son verdaderos hombres y que no sólo son capaces de entender la fe Católica, sino que, de acuerdo con nuestras informaciones, se hallan deseosos de recibirla.

Deseando proveer seguros remedios para estos males, definimos y declaramos por estas nuestras cartas, o por cualquier traducción fiel, suscrita por un notario público, sellada por cualquier dignidad eclesiástica, a las que se les dará el mismo crédito que a las originales, no obstante lo que se haya dicho o se diga en contrario, tales indios y todos los que más tarde se descubran por los cristianos, "no pueden ser privados de su libertad por medio alguno, ni de sus propiedades, aunque no estén en la fe de Jesucristo y de sus efectos."

También hacía referencia a su libertad pero esta parte parece que se olvidó por el camino:

Bartolomé de Las Casas ${ }^{9}$, defensor de los indios pero partícipe de la esclavitud africana para reemplazar la mano de obra indígena y para según él salvar a los indígenas de la extinción por el trabajo forzoso que imponían los españoles y que le estaba causando la muerte.

Después de la llegada de Cristóbal Colón, los españoles vieron en América un lugar ideal para la colonización híbrida tropical y esclavista. Deseando enriquecerse, abrumaron a los aborígenes con trabajos superiores a sus fuerzas. En 1517, Fray Bartolomé de las Casas, temió la extinción de estos y, como medida de salvación, pidió a los Reyes Católicos esclavos negros.

No debemos olvidar el aporte que África hizo a América, al darnos a sus mejores hijos, y como las Casas lo pensó, sin ellos, nuestros indios no hubieran sobrevivido. El propio Bartolomé de las Casas, que había sugerido importar esclavos negros para salvar la existencia de los indios, después comprendió que también era inmoral y anticristiano esclavizar los negros como escribió en su libro Historia de las Indias que se publicó 350 años más tarde.

\footnotetext{
6 Karl Marx, fue un filósofo, economista, sociólogo, 1 periodista, intelectual y militante comunista prusiano de origen judío.

7 Dr. Eric Eustace Williams (n. en Trinidad, 25 de septiembre de 1911 - m. en Puerto España, 29 de marzo de 1981) fue el primer Ministro de Trinidad y Tobago y un notable historiador. Se dedicó a la política desde 1956 hasta su muerte en 1981.

8 Juan Pablo II (en latín: Ioannes Paulus II), de nombre secular Karol Józef Wojtyła (Wadowice, Polonia, 18 de mayo de 1920, Ciudad del Vaticano, 2 de abril del 2005), fue el papa 264 de la Iglesia Católica y soberano de la Ciudad del Vaticano desde el 16 de octubre de 1978 hasta su muerte en 2005 . Fue canonizado en 2014, durante el pontificado de Francisco.

9 Fray Bartolomé de Las Casas (Sevilla, 1474 - Madrid, 1566) Religioso español, defensor de los derechos de los indígenas en los inicios de la colonización de América. Tuvo una formación más bien autodidacta, orientada hacia la teología, la filosofía y el derecho.
} 
El comportamiento de la Iglesia Católica en los siglos quince y dieciséis, obligó al Papa Benedicto XVI ${ }^{10}$ a proferir las siguientes palabras, "herida grave infligida a la justicia y la paz" fue la esclavitud de negros y africanos, apoyada por la Iglesia Católica. Pero, ¿saben nuestros jóvenes afrodescendientes todo esto? ¿Saben acaso que no importa cuál sea su apariencia exterior o su lugar de procedencia, son africanos en su origen y complejidad genética? ¿Saben que los primeros y más prodigiosas civilizaciones del mundo brotaron del suelo africano manteniéndose durante milenios y garantizando para todos el comienzo de las ciencias, de la arquitectura, de la organización política, de las artes, de la religión? Como lo van a saber si nuestros sistemas educativos han negado el derechos de la población negra afrodescendiente a conocer su pasado y por eso ha sido difícil construir su futuro. Les han negado su identidad.

Precisamente ha sido por la falta de este conocimiento el que ha incitado a millones de personas, incluidos niños y adolescentes, a nutrir todo tipo de perjuicios y odios contra sus compañeros de escuela y vecinos de piel oscura descendientes de África, y ha sido una de las causas principales de la exclusión de los pueblos afrodescendientes en la vida política, económica, social y cultural en nuestros países.

\section{Para construir el futuro hay que conocer el pasado}

Desde finales del siglo XIX la consolidación y hegemonía de los Estados Nacionales, sistema heredado de la colonia española, se da a través de un proceso de educación homogeneizante que invisibiliza y trata de destruir la diversidad étnica cultural del continente, implementando escuelas monolingües y públicas entre la población autóctona. En estos sistemas educativos se esconde y se invisibiliza la historia de los pueblos afrodescendientes.

La orden neo colonizadora de los Estados Nacionales, establece como forma de supremacía una jerarquía lingüística, donde el español o castellano y el portugués predominan sobre las lenguas de los pueblos. Las lenguas maternas de las culturas asentadas en el continente fueron perseguidas y remitidas al uso casi encubierto de la marginalidad. De ahí que el proceso de castellanización de la educación a través del lenguaje, es la imposición y reproducción de la hegemonía del español y portugués.

Jurídicamente, las identidades nacionales se configuraron a partir de la negación de la diversidad y de sus raíces étnicas y culturales. En el Marco del Estado Nación mono cultural se construyó un concepto de ciudadanía que reconocía sólo a quien fuera mestizo de habla español y católico. Esta concepción excluyente se consagró como el derrotero de las políticas estatales, creando una cultura política discriminadora y excluyente, que hoy se convierte en una de los principales escollos a vencer para generar procesos de reconocimiento e inclusión de la identidad y cultura de los pueblos indígenas y afrodescendientes.

La búsqueda y la configuración de una sola identidad partiendo de la negación e invisibilidad de nuestra diversidad, no nos ha permitido descubrir y disfrutar la inmensa riqueza que tenemos. El Estado de Nicaragua, aunque muy poco estudioso de los afrodescendientes en América Latina lo reconoce, fue con la Constitución de 1987 que marcó el hilo de los derechos humanos de los pueblos indígenas y afrodescendientes al tener consagrada en el artículo 8 de la mencionada Constitución que Nicaragua es un país multiétnico, plurilingüe y pluricultural. Este precepto constitucional dio visibilidad a los pueblos indígenas y negros que por primera vez en la historia se sintieron ciudadanos de ese país. Este Marco jurídico selló una revolución en los países latinoamericanos, cuyos gobiernos negaban la existencia de los pueblos indígenas y negros a pesar que en muchos de estos países su población era mayoritariamente indígenas o negros.

Así vemos en el Brasil en su constitución de 1988 un año después a la de Nicaragua, marca un paso en el camino correcto para los afrodescendientes brasileños al establecer en la mencionada constitución que en su artículo 5 incluye el principio de igualdad y el artículo 68 establece que la comunidades de quilombos han de tener la propiedad definitiva de las tierras que ocupan quedando el Estado Federal en la obligación de entregarles sus títulos. Pero lo importante de esta constitución brasileña de 1988 que dio pie para un

\footnotetext{
${ }^{10}$ Benedicto XVI (en latín, Benedictus PP. XVI), de nombre secular Joseph Aloisius Ratzinger ( Baviera Alemania, 16 de abril de 1927), fue el papa número 265 de la Iglesia católica y séptimo soberano de la Ciudad del Vaticano. Resultó elegido el 19 de abril de 2005 tras el fallecimiento de Juan Pablo Il, por los cardenales que votaron en el cónclave.
} 
sin número de leyes y decretos que vinieron a favorecen al pueblo negro brasileño como son la Ley 7,716 Ley Anti-Racista sobre la penalización de la discriminación racial. La Ley 10,678 sobre la Enseñanza de la Historia y Cultura Afrobrasileña y africana. El Decreto 4,428, Programa Nacional de Acciones Afirmativa, entre otras leyes y decretos.

También en Colombia en su constitución de 1991 en su artículo 13 establece el principio de la igualdad y la no discriminación racial asimismo el artículo 55 establece la creación de una ley y una comisión especial que reconozca a las comunidades negras el derecho de la propiedad colectiva. Igualmente la Constitución Colombiana de 1991 dio lugar a una serie de leyes que vinieron a beneficiar la población negra colombiana como son la Ley 70 de Comunidades Negras, 1993. Resolución 071 sobre Representantes a la Cámara por la circunscripción Nacional especial para las comunidades negras. Decreto 2314 que crea la Comisión de Estado para la formulación del Plan de Desarrollo de las comunidades Negras, entre muchas otras leyes y decretos a favor de la población negra colombiana.

La Ley 70, es el instrumento principal o más importante en materia de igualdad para los afrodescendientes colombianos, pues establece el reconocimiento de los derechos, económicos, sociales y culturales para insertar en la sociedad colombiana en igualdad de condiciones con el resto de la población.

En el caso del Ecuador en el artículo 3 de la Constitución del 2008, establece la responsabilidad del Estado de garantizar la igualdad y la no discriminación. La Constitución antes mencionada dedica el capítulo IV a la garantía de los derechos de las comunidades, pueblos, y nacionalidades que defina en el artículo 56, como las comunidades, pueblos y nacionalidades indígenas, pueblos afro ecuatorianos y las comunas forman parte del Estado Ecuatoriano único e indivisible.

Igualmente como en el Brasil y Colombia, la Constitución de 2008 sienta las bases para una serie de Leyes como la 275, Decretos y Acuerdos Ministeriales a beneficio de la población afro ecuatoriana. Podemos mencionar países como Panamá, Costa Rica y Honduras que tiene legislación en beneficio de los pueblos afrodescendientes.

Pero a pesar de los grandes esfuerzos que han hecho algunos gobiernos para erradicar la pobreza mediante acciones afirmativas, la realidad nos han mostrado que no han sido suficientes para erradicar las desigualdades y la pobreza y extrema pobreza del pueblo afrodescendientes aquí en la América Latina. Esto nos demuestra que el racismo y la discriminación hacia el pueblo afrodescendiente no nos han permitido llegar al fondo del problema para erradicar par siempre la desigualdad, la pobreza y extrema pobreza en que están sumergido. Señores y señoras solo mediante una educación de calidad es que realmente podemos erradicar este mal de nuestro pueblo.

"la educación es una de las variables que tiene mayor influencia sobre el progreso individual y social" Por otro lado, según (De Moura, Navarro, Wolf y Cabrol, 1998, p. 1) "la educación es percibida cada vez más, y con razón, como un elemento vital para el desarrollo económico, la reducción de la pobreza y la disminución de las desigualdades en el ingreso." La educación pública de nuestros países tiene muchos males. Tanto que los esfuerzos que se hacen para mejorar la educación resultan insuficientes y los Ministerios de Educación, hasta ahora, no demuestran que la educación de nuestros países es la prioridad.

El sistema educativo de nuestros países tiene insuficiencia crónica de capacitación docente, que es la columna vertebral de la calidad educativa. También tiene insuficiencia de políticas públicas que obliguen al país a cumplir con el calendario escolar para por lo menos, acercarse a los estándares mínimos de calidad.

A través de un buen direccionamiento de las políticas educativas se debe lograr una adecuada preparación de los jóvenes para que se incorporen a la fuerza laboral. A como decía Savater ${ }^{11}$ : Muchas veces he dicho que la educación es el instrumento para luchar contra la fatalidad social, contra esa fatalidad que

\footnotetext{
${ }^{11}$ Fernando Fernández-Savater Martín (San Sebastián, 21 de junio de 1947) es un filósofo e intelectual español. Novelista y autor dramático, destaca en el campo del ensayo y el artículo periodístico.
} 
hace que el hijo del pobre siempre tenga que ser pobre, que el hijo del ignorante siempre tenga que ser ignorante.

Con esta visión estoy profundamente convencido que para el desarrollo de nuestras pueblos afrodescendientes de la América Latina y el Caribe, para el buen vivir de nuestros pueblos para el bienestar de nuestras comunidades, había que luchar para revertir este concepto llegando a la conclusión que la educación es el instrumento idóneo para producir el cambio que rompa la cadena de la fatalidad social. Pero tiene que ser una educación integral, una educación revolucionaria, una educación descolonizadora, una educación transformadora, una educación que fortalece la identidad étnica, una educación que articula los saberes ancestrales con la tecnología moderna, una educación que respete a nuestra diversidad étnica, una educación de convivencia pacífica y armoniosa a pesar de la diversidad étnica que compone nuestras países de la América Latina y el Caribe, una educación que nos conduzca a conocer nuestro pasado para que de allí construir nuestro futuro, una educación con valores ancestrales, en otras palabras una educación intercultural.

Para lograr esta transformación necesitamos el concurso de todos, autoridades universitarias comprometidas a impulsar el Modelo Pedagógico que nos permite hacer las transformaciones, docentes que aceptan este reto, estudiantes receptivos al cambio, padres de familia dispuestos a seguir sacrificando para el bienestar de sus hijos, los políticos y la sociedad civil dispuestos a brindar todo el apoyo.

Las universidades deben contribuir a que los pueblos afrodescendientes puedan ejercer sus derechos a practicar y revitalizar sus tradiciones y costumbres culturales, lo que implica el derecho a desarrollar y transmitir a las generaciones futuras sus historias, idiomas, tradiciones orales, filosofías, sistemas de escrituras y literaturas. Debiendo el Estado proporcionar los medios necesarios para tal cometido.

Lograr una verdadera interculturalidad en nuestras universidades va muchos más allá de un simple abordaje multilingüístico que se basa en acciones afirmativas hacia pueblos afrodescendientes, que son importantes pero no suficientes. Acciones afirmativas que van desde cupos en las Universidades, becas fuera y dentro de los diferentes países entre algunas cosas.

Para incluir a los que siempre han estado excluidos, es necesario y urgente, desarrollar un nuevo paradigma de la Educación Superior, un paradigma que permita el verdadero empoderamiento de los pueblos originarios y afrodescendientes, un paradigma de enseñanza en el que los estudiantes de estos pueblos pueden aprender desde la investigación de sus propias historias, sistematizar las buenas prácticas de sus pueblos, intercambiar desde sus propias lenguas sin ser tildados de menos por hacerlo.

Los pueblos indígenas y afrodescendientes hoy les invitan a que, siguiendo el rastro de la sabiduría ancestral y reconociendo el valor de su cultura e identidades, consolidando nuestra historia donde se conjuga una lucha profunda de constante resistencia por la defensa de nuestro origen a través de procesos propios de madurez y autonomía intelectual como base fundamental para el desarrollo de capacidades, que ciertamente hemos poseído pero forzosamente vistos como inciertas por todas aquellas circunstancias extrajeras y oportunistas, unas más violentas que otras pero igual con el mismo fin, la amenaza relevante de la pérdida de nuestra identidad.

Entre una de las declaraciones de la CRES, se plantea que se debe de promover la diversidad cultural y la interculturalidad en condiciones equitativas y mutuamente respetuosas. Que el reto no es sólo incluir a indígenas, afrodescendientes y otras personas culturalmente diferentes en las instituciones tal cual existen en la actualidad, sino transformar a estas para que sean más pertinentes con la diversidad cultural. Planteo también, que es necesario incorporar el diálogo de saberes y el reconocimiento de la diversidad de valores y modos de aprendizaje como elementos centrales de las políticas, planes y programas de la Educación Superior. 
Como pueden ver estimada audiencia, el reto es grande, necesitamos una educación integral no solamente una educación instructiva de conocimiento, como las que reciben los estudiantes en las grandes universidades tradicionales; pero, además una educación formativa, que hace énfasis en los valores como la honestidad, la puntualidad, la limpieza, el respeto, una educación intercultural que promueve un cambio de actitud ante la naturaleza y un cambio de actitud ante la vida misma, creo que juntos lo podemos lograr, juntos podemos construir el camino que nos lleva al buen vivir, vivir bien y vivir con dignidad de nuestros pueblos, y que efectivamente los pueblos afrodescendientes de América Latina y el Caribe puedan decir hoy somos ciudadanos de los respectivo países.

Considero que el abordaje intercultural en la Educación Superior no es sólo un reto, es también de mayores desafíos para las universidades indígenas e interculturales. Pero también esto debe ser un reto para todas las instituciones formadoras de recursos humanos de nuestros países de América Latina y el Caribe que siendo marcadamente multiétnicos, multilingües y pluriculturales, deben desarrollar las capacidades para permitir la inclusión de cada uno de nuestros pueblos y cultura. Esto sin duda alguna enriquecerá sustancialmente el acervo cultural de nuestras naciones, con énfasis en divulgación y difusión de los nuevos valores de la identidad propia de la africanidad: la negritud es humanismo. En la parte académica debe afianzarse en el eje de la interculturalidad, venciendo los prejuicios.

\section{Declaración de las Naciones Unidas sobre los derechos de los pueblos indígenas}

La metáfora fundacional de los pueblos originarios en la historia y del pueblo africano en este caso concreto ha marcado este hito producto de la escasez mental, espiritual y material del Viejo Mundo europeo. La africanidad comprende los africanos y afrodescendientes que actualmente habitan, sobreviven y viven en el afán de empoderarse en la virtud inherente a su dignidad en los siglos de resiliencia para afirmar la pluridiversidad en los derechos consagrados de los seres humanos, ahora, ayer y mañana en el fluir ancestral de su universo en pleno siglo XXI y en este puente de la consciencia nace la solidaridad hacia los africanos que actualmente se ven obligados a migrar hacia los países del Norte y de sus derechos inalienables proclamados por la Declaración Universal de los Derechos Humanos, la Declaración de las Naciones Unidas sobre los derechos de los pueblos indígenas, el Convenio 169 de la OIT. Han cambiado los viejos actores y los directores de la película, pero lo real sigue en lo mismo, en el casi-casi de que algo se concrete para un cambio del desarrollo integral humano que es la vocación que nos caracteriza, empoderarnos en el desarrollo auto sostenible, ser alegres, cantores, bailarines, amistad y amor desde nuestras costumbres y tradiciones ancestrales, dispuestos a cambios de paradigmas innovadores, con derecho de acceso a la ciencia y a la transferencia de tecnologías que se nos ha negado. Para lo cual nos preparamos en este largo sendero de contradicciones que se agudizan para la existencia misma en el planeta azul porque el mundo se ha globalizado, la crisis es civilizatoria. Exige de nosotros un posicionamiento de valores humanos, avezado movimiento de coaliciones y alianzas para proclamarse en la dignidad como continente y ser de humanidad en cuanto a los derechos humanos. Esta es una singular afirmación en la necesidad del ser para afrontar sus necesidades de pertinencia, entre ellos el derecho a la educación y la salud con calidad y que ya deje de ser la oficial monocultural, sino la que atienda la pluridiversidad con una educación intercultural bilingüe y se afirme la categoría de todos los derechos de ciudadanía, asimismo ponderar la participación de la mujer en los espacios políticos de participación democrática y ciudadanía, a una gobernabilidad que le permita desde la equidad del género su reconocimiento en los derechos establecidos en la Declaración Universal de los Derechos Humanos, se necesita la reafirmación de los Estados plurinacionales y las leyes y mecanismo que permitan la viabilidad de esta gobernanza en equidad y justicia que logren desarrollar a plenitud la integridad del ser humano, la correspondencia real entre ley y realidad.

\section{Pero ¿cuáles son las verdaderas causas de la migración africana?}

Ni un sólo medio de comunicación ha mostrado preocupación de saber las verdaderas causas de la migración africana, antes bien se ha tildado esta migración como una "invasión" o "avalancha" con lo cual se les toma como chivo expiatorio por los gobiernos de Panamá, Costa Rica y Nicaragua y en este infraganti se comete delito de discriminación y omisión, en vez de presentar con claridad la esencia del 
conflicto, utilizan la figura de la "repatriación" que no es más que abandonar a la suerte a la población africana y quienes ante esta violación a los derecho humanos y ciudadanos han retomado rutas alternas de alta peligrosidad arrojándolos a la muerte: matándolos a tiros en senderos de montaña, donde se han ahogado, algunos han desaparecido y se mantiene en el ambiente mutis o silencio total y por parte de los periódicos amarillistas no existe seguimiento informativo; no obstante, la tragedia continua con una ofensiva permanente de persecución y en tanto dicho crimen masivo se mantiene, los gobiernos alegan que es en defensa y control de la soberanía, se suma a estos hechos la manipulación política de las multilaterales como el Fondo Monetario Internacional, el Alto Comisionado de las Naciones Unidas, Banco Mundial, Banco Interamericano de desarrollo.

Las verdaderas causas de la migración africana son: las crisis económicas, guerras, hambrunas, miserias, precariedad, dictaduras, crisis civilizatoria, ecológica y política, catástrofes naturales, expoliación de los recursos naturales, la corrupción entre los gobiernos locales africanos con los monopolios foráneos, etc. Junto a la descomposición política de los Estados africanos desde la década de los ochenta, todos estos aspectos se han convertido en poderosos factores de emigración de los africanos y son los verdaderos efectos de expulsión hacia los países más ricos.

La pobreza y el subdesarrollo económico que padece el continente africano son esenciales para comprender las causas de este fenómeno. Durante la época del colonialismo de los siglos XVIII, XIX y principios del XX, que trajo de forma paulatina la independencia y el gobierno autónomo a estos países se encuentra la raíz del neocolonialismo, y la corrupción que vivimos hoy y que ha dado lugar al "crecimiento sin desarrollo" de África.

Tras la descolonización, las potencias coloniales sólo se encargaron de la explotación de los recursos naturales con la complicidad de los gobiernos locales. África necesita una segunda descolonización. Actualmente África vive una honda situación paradójica entre sobrevivir o morir. Aunque el continente se halla inmerso en una profunda crisis económica, y la pobreza es inmensa, sus élites políticas han acumulado una enorme riqueza. Se calcula que las fortunas ocultas en bancos extranjeros (sobre todo en Suiza) son prácticamente equiparables al total de la deuda externa del continente. Según Chabal, también "existen algunos dirigentes africanos que continúan amasando fortunas ciclópeas a pesar del colapso total en que se hallan los países de los que se benefician". Puedes tener todo y disfrutar de todo el dinero del mundo, pero de la muerte no se salva nadie. Cómo podemos hacer entender a estas personas que de este mundo en que vivimos no van a llevar nada. Tenemos un tiempo limitado para vivir en esta Tierra; uno debe tratar de usar este período para el propósito de transformar nuestros países en lo que uno desea que fuera para que todos puedan gozar del buen vivir, vivir bien y vivir con dignidad.

\section{¿Cómo se puede generar tanta riqueza en semejantes condiciones?}

El enriquecimiento sin el desarrollo que padece África depende, esencialmente, de tres factores fundamentales.

El primero, el continente cuenta con suficientes recursos naturales con los que comercian legal o ilegalmente quienes ostentan el poder. Los beneficios obtenidos son, parcial o totalmente, desviados a las élites políticas o a los "señores de la guerra" que controlan la zona. Además, una gran parte de la explotación de los recursos naturales ha sido transferida o vendida a las grandes corporaciones multinacionales o a los gobiernos de los países desarrollados.

En segundo lugar, aunque los Programas de Ajuste Estructural pretendían que el mercado escapara de la influencia del Estado, la realidad es que han servido para reforzar la posición de las élites políticas, ya que han puesto en sus manos gran cantidad de recursos financieros. Esta situación, unida a la oleada privatizadora de los propios recursos que ha calado en África desde décadas, causante de que gran parte de las inversiones y no tengan una incidencia real en los índices de desarrollo. 
El tercer aspecto es precisamente las inversiones que recibe la región. Aunque cuantiosas, no se convierten en fuente de crecimiento económico por la ineficiente distribución de los recursos que malversa la clase dirigente. Ésta se encuentra cada vez más involucrada en transacciones financieras y comerciales de carácter ilegal, desde blanqueo de dinero (como se demostró documentalmente en el caso del Banco de Crédito y Comercio Internacional) hasta tráfico de drogas (se dice que los nigerianos dominan el mercado en Nueva York).

\section{África no es simplemente la víctima de la globalización}

Sus élites participan activamente en el mercado extraoficial a nivel mundial, mientras millones de africanos se empobrecen porque la riqueza que circula por el continente no estimula ningún desarrollo económico sostenible. Para quienes prosperan de la economía global extraoficial, el enriquecimiento sin desarrollo es una situación tendenciosa.

La verdadera causa de la emigración africana es la existencia de unas élites políticas corruptas cada vez más ricas que impulsan a que el resto de la población sea cada vez más pobre, con la complicidad de gobiernos y corporaciones transnacionales. Lo preocupante es calificar la migración como un delito, con su consiguiente criminalización, y no como un derecho: el derecho a la vida y a la supervivencia y una negación a compartir todo desde el hogar y la familia.

\section{Criminalizan migración africana en pleno siglo XXI}

\section{Hermandad o racismo en los gobiernos de Centroamérica}

Las acciones de los Gobiernos de Panamá y Costa Rica en los últimos meses enfatiza el control fronterizo y las políticas de seguridad que no sólo no han dado una solución a las causas de la migración de los africanos hacia EE.UU., sino que de facto han acentuado la criminalización de los migrantes; también un grupo tras alcanzar la frontera con Nicaragua fue devuelto hacia Panamá, han pasado más de 30 horas a la intemperie, después de que este último país les negara el ingreso, en detrimento de los derechos humanos de los africanos en tránsito, así al aumento notorio de la vulnerabilidad físico-emocional y socioeconómica expuestos.

Con el cierre de fronteras se manifiesta una afirmación del tabú y prejuicio que no resuelve el problema humanitario al trastocar su futuro y su cultura, sin atender las razones y causas de su migración. Estas medidas sólo postergan y coadyuvan al flagelo de los migrantes. Lo último es reafirmado por los medios de comunicación masivos, que manifiestan un vacío tendencioso informativo al no abordar el tema con claridad objetiva, ni justicia social en rejuego de la manipulación política de los gobiernos. Estos ciudadanos más que ser preciados como sujetos que padecen situaciones de precariedad material y violencia estructural, son tratados como criminales por las autoridades racistas ticas-panameñas por el gobierno de Nicaragua, en lugar de ser tratados como refugiados en la búsqueda de otras opciones de vida y que huyen de la adversidad en donde está en juego su vida e integridad física y un proyecto de futuro digno, antes bien se les ha etiquetado como infractores de la ley.

Los Gobiernos de Panamá y Costa Rica no cumplen la ley para que se castiguen los delitos contra los migrantes, y sí propicia entornos de impunidad y violencia ignorantes del tema de la africanidad; cometiendo delito de omisión ante las bandas del crimen organizado, funcionarios y miembros de los aparatos represivos (fuerza pública) lucren con los migrantes y se aprovechen de su indefensión con la violación de los derechos humanos de estos africanos.

Ante este nuevo fenómeno migratorio a través del istmo panameño las instituciones no gubernamentales que "velan" por los derechos humanos en Panamá no han dado las respuestas correspondientes al hecho. Por otra parte, las instituciones eclesiásticas atraviesan crisis cultural y conceptual al señalar el fenómeno migratorio como de caridad, ignorando el problema de fondo y al no enfocarlo en toda su plenitud, existen otras manifestaciones de racismo. Esto reafirma que no comprenden la raíz ni el ámbito social de este fenómeno. Ser negro y ser emigrante implica que deben duplicarse los esfuerzos que deben 
llevar a cabo estos grupos humanos para ser tratados como sujetos de derecho. En ese mismo sentido, el Mes de la Etnia Negra fue celebrado en Panamá como parte de la influencia de la sociedad del espectáculo y circo, limitándolo al baile, la música y la gastronomía que heredamos de los secuestrados que llegaron al continente en condición de esclavos, olvidándose del presente inmediato que da muestra de la hipocresía, el racismo, la ineptitud y olvido de la comprensión cultural de nuestros gobernantes actuales.

\section{En el dédalo de cinco siglos de esclavitud a la crisis civilizatoria}

La crisis civilizatoria es el sendero o sea el faro de la luz para guiarnos en el retorno de ultramar, ya no miramos la salida del túnel, al final sólo desesperanza y hastío que genera ceguera, una cadena degenerativa porque al conculcar los legítimos derechos, castra al individuo, al colectivo y a grupos sociales como si fuésemos topos a sobrevivir en los subterráneos porque la discriminación y la corrupción se manifiestan como hechos correctos y normales en las instituciones gubernamentales y eclesiásticas, entes autónomos, sector empresarial y en la vida cotidiana. En esta nueva fisura y nueva forma de esclavitud los africanos ya no son desmembrados de su origen por las potencias europeas, en referencia a ese pretérito de vergüenza histórica:

como esclavos que se les apiñaba en forma apretada en buques de carga, de 300 a 450 por barco, y se les encadenaba en bodegas o calas sin instalaciones sanitarias ni suficiente espacio para permanecer de pie y permanecían así durante su largo viaje a América, el cual duraba por lo menos cien días. La tasa de mortalidad alcanzaba diez por ciento, excepto viajes más largos, en los cuales, debido a tormentas o vientos adversos, la tasa llegaba a ser más alta. Los africanos que sobrevivían al viaje estaban expuestos a enfermedades ante las que tenían poca o ninguna inmunidad ${ }^{12}$. Sino que en la hecatombe mundial se ven forzados a la migración hacia un "mundo de progreso".

Para el historiador británico Hugh Thomas en su obra La trata de esclavos, confirma que la esclavitud fue abolida el siglo XIX, pero el tráfico esclavista de mano de obra humana continua, aunque no institucionalizada, en países como Mauritania y Sudán, a su juicio, los esclavos de este siglo veintiuno viven en peores condiciones que los del siglo XV.

Thomas, que ha dedicado cinco años a la investigación de La trata de esclavos, desde sus inicios portugueses en el siglo XV hasta sus finales en Cuba en el XIX, cree que los citados países no son los únicos que traficaron con seres humanos, cita la situación vivida en los campos de concentración nazi, los campos de detenidos políticos rusos o la explotación de que son objeto ahora algunos emigrantes ilegales. En este último caso, la situación puede llegar a ser tan desesperada que seguramente preferirían vivir como las personas que trabajaban en las haciendas de azúcar cubanas o en las plantaciones estadounidenses: "Viven peor que en el siglo XV, pero la diferencia es que al menos les queda la posibilidad de cambiar de vida", dijo el historiador.

Actualmente los vemos de paso como ese vuelo migratorio de los pájaros marinos. Pero, allí yacen estancados en la ruindad de los sistemas aduaneros que cortan el sueño que se ha concretado en los milenios de la existencia humana. La solidaridad implica la ley de correspondencia, no sólo de la consciencia humilde y superior del amor del uno hacia el otro, sino de los mismos Estados por cumplir los tratados y convenios internacionales en materia de los derechos humanos, los cuales son principios dinámicos que deben observarse en el camino de la perfectibilidad. Sin embargo, esto además de visibilizarse sigue en la misma rutina, y hemos aprendido a guardar silencio ante la injusticia y lo injusto. Decía Martin Niemöller ${ }^{13}$ en su famoso poema, Ellos vinieron

\footnotetext{
$\overline{12}$ Thomas Trotter (1760-1832) was a Scottish naval physician and author who was a leading medical reformer in the Royal Navy and an ardent critic of the slave trade. Trotter was born in Melrose, Roxburghshire, and studied medicine under Alexander Monro (secundus) in Edinburgh. La trata de esclavos. Hugh Thomas. Planeta, Barcelona, 1998.

${ }^{13}$ Friedrich Gustav Emil Martin Niemöller (Lippstadt, Renania del Norte-Westfalia, 14 de enero de 1892-Wiesbaden, Hesse, 6 de marzo de 1984) fue un pastor luterano alemán y antinazi.
} 
Cuando los nazis vinieron a llevarse a los comunistas,/guardé silencio,/ porque yo no era comunista./ Cuando encarcelaron a los socialdemócratas,/ guardé silencio,/ porque yo no era socialdemócrata./ Cuando vinieron a buscar a los sindicalistas,/ no protesté,/ porque yo no era sindicalista./ Cuando vinieron a llevarse a los judíos,/ no protesté, porque yo no era judío./ Cuando vinieron a buscarme,/ no había nadie más que pudiera protestar.

Friedrich Gustav Emil Martin Niemöller

Cada uno es responsable de estas reglas del dominó y de quién somete a quién. Esto debe cambiar, renovarnos para resurgir y mirarnos francamente y prodigarnos de amor. Miles y miles de migrantes africanos yacen varados en su paso migratorio por América Latina hacia el encuentro con su familia en el Norte de los Estados Unidos. Los funcionarios de las repúblicas en América Latina, los edecanes de los organismos internacionales no ejercen su labor de paz y amor por las cuales devengan un salario, esa es la prueba de la manifestación de los entes individuales que laboran para las Naciones Unidas como el Alto Comisionado de las Naciones Unidas para Refugiados (ACNUR). Su arbitrariedad de no cumplir con los mandatos de los derechos humanos los hace dogmáticos de la indiferencia. Un caos que no permite que todos vibremos en energía positiva, fluir la paz y la realización de la humanidad. Este obstáculo es el mayor en la incidencia de las promesas vacías. Decía John F. Kennedy ${ }^{14}$ :

"The hottest places in hell are reserved for those who, in times of moral crisis, maintain their neutrality" "Los lugares más calientes del infierno están reservados para aquellos que, en tiempos de gran crisis moral, mantienen su neutralidad".

En pleno siglo veintiuno nos encontramos indiferencia al sufrimiento de los centenares de africanos, ante ello preguntamos cual es el grado de correspondencia hacia nuestro prójimo. Nadie sabe del dolor ajeno, hasta que no lo muerde en el propio zapato. El asunto desde luego no es de suelas, sino el vivírselas aprendiendo a convivir en un sentido de humanidad.

\section{Coalición y unidad ante la indiferencia racista}

Debemos enriquecernos en el alma para alzar vuelo hacia lo espiritual. Nada es ajeno a la consciencia y esta es praxis desde la cotidianidad con nuestro habérnosla, esto es un compromiso con nosotros y la sociedad. Deben mancomunarse nuestras ideas, nuestras almas, nuestro sentir y vibrar. El destino es la realización de la humanidad y el amor. Por eso avanzar hombro con hombro es la manifestación de nuestra pertinencia ante nuestro ambiente y espacio, tanto el que se internaliza y el que se devela como una oportunidad de empoderar en lo social esa raíz de consideración hacia el otro. No estamos ajenos al derecho positivo o internacional, nos reafirmamos en la Declaración de los Pueblos Indígenas de Naciones Unidas y todos aquellos instrumentos internacionales que ponderan la dignidad del ser humano.

En cuanto al liderazgo de las Universidades Comunitarias e Interculturales estas asumen el acompañamiento en la pluridiversidad, debemos abrir el abanico a la contigüidad de los otros en cuanto a coaliciones y alianzas del buen vivir. En el caso actual de la migración de los pueblos africanos, debemos construir los andamiajes para que nuestros hermanos no sean invisibilizados ni marginalizados en la diáspora del siglo veintiuno. Se debe prestar todos los apoyos materiales e intangibles para que su migración no sea infernal, que crezca nuestra semilla con la dulzura de compartir y fortalecer su vuelo migratorio, el asentamiento de la identidad africana porque no puede haber desarraigo, sino acentuación de las raíces.

Hermanas y hermanos el reto es grande, la lucha sigue, no debemos seguir lamentando los siglos de injusticia. Tenemos el deber y el derecho de seguir con la frente y moral en alto honrando el sudor, la sangre y la muerte de nuestros ancestros. En consecuencia, se hace un llamamiento a nuestros más de 200 millones de afrodescendientes de las Américas y el Caribe para tomar consciencia en la unidad y en el

\footnotetext{
14 John Fitzgerald Kennedy (Brookline, Massachusetts, 29 de mayo de 1917-Dallas, Texas, 22 de noviembre de 1963) fue el trigésimo quinto presidente de los Estados Unidos Elegido en 1960, Kennedy se convirtió en el presidente más joven de su país, después de Theodore Roosevelt. Ejerció como presidente desde el 20 de enero de 1961 hasta su asesinato el 22 de noviembre de 1963.
} 
ejercicio de la restauración de todos y cada uno de los derechos que nos asisten históricamente, en especial del presente decenio internacional de los afrodescendientes.

El 28 de agosto de 1963 el inolvidable Martin Luther King Jr ${ }^{15}$. desde la escalinata del Monumento de Lincoln, pronunció uno de los insignes discursos de la Historia "Yo tengo Un Sueño. Yo tengo un sueño que un día esta nación se elevará y vivirá el verdadero significado de su credo, creemos que estas verdades son evidentes, que todos los hombres son creados iguales. Yo tengo un sueño que un día mis cuatro hijas pequeñas vivirán en una nación donde no serán juzgados por el color de su piel sino por el contenido de su carácter.

Yo tengo un sueño que los hijos de los ex esclavos y los hijos de los ex propietarios de esclavos serán capaces de sentarse en la mesa de la hermandad. Yo tengo un sueño que un día pequeños niños negros y pequeñas niñas negras serán capaces de unir sus manos con pequeños niños blancos y pequeñas niñas blancas como hermanos y hermanas.

También nosotros tenemos un sueño que un día los niños y niñas negras, indígenas, blancas y mestizas y de todas las razas unidas en hermandad, forjemos una unidad, justa y equitativa a favor del género humano.

No odies ni desprecies a nadie, porque un solo átomo puede desencadenar un infierno. Ámate como el sudor y la leche, como el infinito amor en los pasos de la Vía Láctea. La educación es el camino para transformar a la gente y para el desarrollo de su bienestar individual y social. La educación intercultural jamás dejará que se muera el sol antes que hayan muerto tus rencores.

$\overline{15}$ Martin Luther King, Jr. (Atlanta, 15 de enero de 1929-Memphis, 4 de abril de 1968) fue un pastor estadounidense de la Iglesia bautista1 que desarrolló una labor crucial en Estados Unidos al frente del movimiento por los derechos civiles para los afro estadounidenses y que, además, participó como activista en numerosas protestas contra la Guerra de Vietnam y la pobreza en general. 


\section{Lista de referencias}

André Gunder Frank (1979). La Acumulación Mundial 1492-1789. p. 266.

Bula Papal 1458. Bula Papa Sublimis Deus. Promulgada por el Papa Paulo III el 2 de junio de 1537.

Bartolomé de las Casas (1527 y 1559). Historia de las Indias.

Constitución Política de la República de Nicaragua (1987). Aprobada por la Asamblea Nacional Constituyente el 19 de noviembre de 1986. Publicada en La Gaceta 94, 30 de abril de 1987.

Constitución de la República Federativa del Brasil (1988). Lei do Crime Racial - Lei 7716/89 | Lei n 7.716, de 5 de janeiro de 1989. Ley núm. 10678, de 23 de mayo de 2003, que crea la Secretaría Especial de Políticas de Promoción de la Igualdad Racial de la Presidencia.

Constitución de República de Colombia (1990). Promulgada el 7 de julio de 1991. LEY 70 DE 1993 agosto 27. Colombia. Diario Oficial No. 41.013, de 31 de agosto de 1993.

Constitución de la República del Ecuador (2008).

La Declaración Universal de Derechos Humanos adoptada por la tercera Asamblea General de las Naciones Unidas, el 10 de diciembre de 1948 en París.

El Convenio 169 de la Organización Internacional del Trabajo sobre pueblos indígenas y tribales, Firmado: 27 de junio de 1989; Ginebra, En vigor: 5 de septiembre sw 1991.

La Declaración de las Naciones Unidas sobre los derechos de los pueblos indígenas, adoptada en Nueva York el 13 de septiembre de 2007 durante la sesión 61 de la Asamblea General de las Naciones Unidas

Conferencia Regional de Educación Superior de América Latina y el Caribe (CRES. 2008). Declaración Final de la Conferencia Regional de Educación Superior en América Latina y el Caribe.

Hugh Thomas (1998). La Trata de Seres Humanos de 1440 a 1879- Compuesto de seis libros Author

Marx, Karl. El Capital. Proceso de circulación del capital. Tomo 1. Fondo de cultura Económica. Edición en Español de 1959. Reimpresión de 1995. 